\title{
Design and Comparison of Multistage Axial Flux Permanent Magnet Machines for Potable Generating Application
}

\author{
Jiyoung Lee ${ }^{1,2 *}$, Byounggun Park ${ }^{1,2}$, and Byungchul Woo ${ }^{1}$ \\ ${ }^{1}$ Korea Electro-technology Research Institute, Changwon, Gyeongnam 51543, Korea \\ ${ }^{2}$ Energy and Power Conversion Engineering, University of Science \& Technology
}

(Received 20 July 2015, Received in final form 23 October 2015, Accepted 26 October 2015)

\begin{abstract}
In this study, we present a comparison of multistage axial flux permanent-magnet machines (AFPMs) with different topologies for use as $100 \mathrm{~W}$-class portable generating systems. Three topologies were selected, and the maximum power density and high level of efficiency were achieved by following the response surface methodology (RSM) in the design. Three-dimensional finite element analysis (FEA) was used to conduct numerical experiments to obtain the optimum design using the RSM and suggest a proper configuration of the portable generating system.
\end{abstract}

Keywords : axial flux machine, finite element analysis, generator, permanent magnet machines, response surface methodology

\section{Introduction}

Axial flux permanent-magnet machine (AFPM) has distinct advantages over traditional radial-flux permanentmagnet machines (RFPMs) in terms of a large power density and compact construction resulting from the improved flux utilization and more effective cooling $[1,2]$.

The variable combinations of number of poles and slots have been examined in the design of a generator for a 50 W-class generating system, and the 16-pole and 18-slot combination was selected as the target for the system [3]. Therefore, we used the same number of poles and slots to design a generator for a $100 \mathrm{~W}$-class generating system, considering a multistage topology. Three models were selected for use in multistage AFPMs and examined for their applicability in portable power systems with higher power density and efficiency.

The target application system, design specifications of the generator, and introduction of the three different types of selected topologies are briefly described in Section 2. The optimum design process using the response surface methodology (RSM) is explained in detail in section 3 .

(C)The Korean Magnetics Society. All rights reserved.

*Corresponding author: Tel: +82-55-280-1416

Fax: +82-55-280-1490, e-mail: jylee@keri.re.kr
The characteristics of the three optimum models designed in terms of the maximum power density and efficiency are discussed in Section 4, and the most suitable type is proposed for a power generation system.

\section{Portable Generating System and Multi-stage AFPM}

\subsection{Portable generating system and design specifica-} tions

The design specifications for a $100 \mathrm{~W}$-class portable power generating system using human power are listed in Table 1. A gear was used to reduce the volume and weight of the system, and hence the rated operating speed of the generator was $1800 \mathrm{rpm}$ with a crank speed of 60 $\mathrm{rpm}$. The voltage and current specifications were determined according to the battery of the system. The generating system consists of a crank, gear, generator, and power converter with a rectifier, and the generator is the major system component that determines the power density and efficiency of the system. Therefore, the design of the generator is an important task, and we considered three different types of AFM topologies; a comparison of their characteristics is presented in the next section.

\subsection{Multistage AFPMs}

The conceptual illustrations in Fig. 1 show the three 
Table 1. Specifications for portable generating system.

\begin{tabular}{lll}
\hline \hline Contents & & Values \\
\hline \multirow{2}{*}{ Human power } & Rated speed and speed range $[\mathrm{rpm}]$ & $60(40-80)$ \\
& Expected minimum input power $[\mathrm{W}]$ & 137.5 \\
\hline Gear & Gear ratio & $1: 30$ \\
\hline & Rated speed [rpm] & 1800 \\
& Terminal voltage [Vrms] & 27.3 \\
& Phase current [Arms] & 2.35 \\
& Minimum output power $[\mathrm{W}]$ & 100 \\
Generator & Initial outer diameter $[\mathrm{mm}]$ & 85 \\
& Initial overall height $[\mathrm{mm}]$ & 30 \\
& Material of PM (grade/density $\left.\left[\mathrm{kg} / \mathrm{m}^{3}\right]\right)$ & NdFeB (38UH / 7400) \\
& Material of coil (grade/density $\left.\left[\mathrm{kg} / \mathrm{m}^{3}\right]\right)$ & Copper $(\mathrm{F} / 8933)$ \\
& Material of cores (grade/density $\left.\left[\mathrm{kg} / \mathrm{m}^{3}\right]\right)$ & Soft magnetic composite (somaloy $700-1 \mathrm{P} / 7500)$ \\
\hline
\end{tabular}

multistage AFPMs selected for further examination: NNtype double-rotor single-stator (DR-SS), NS-type DR-SS, and single-rotor double-stator (SR-DS).

The NN-type DR-SS consists of two north-pole magnets facing each other at either side of the stator. Thus, the flux must flow circumferentially around the stator, and a stator yoke is necessary for the magnetic flux flow.

In contrast, the flux can travel straight through the stator without any circumferential flow in the NS-type DR-SS [4, 5]. Therefore, a stator yoke is unnecessary for the magnetic flux flow even though it may be required to provide mechanical strength [6]; however, this is beyond the context of the discussion of this study.

In an SR-DS system, a rotor is placed between the two stators. As with DR-SS systems that can be classified into NN and NS types, SR-DS systems can also be divided into two types depending on the polarities of the stator teeth that are facing each other, because each stator tooth can have different polarity according to the change in the winding direction. However, only the SR-DS with opposite polarities facing each other is considered in this study; therefore, the rotor yoke for the magnetic flux flow is unnecessary.

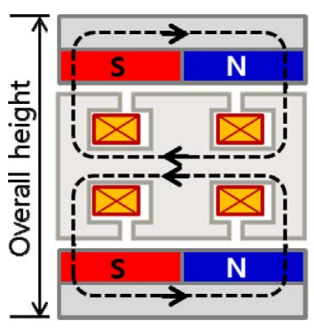

(a) NN type DR-SS

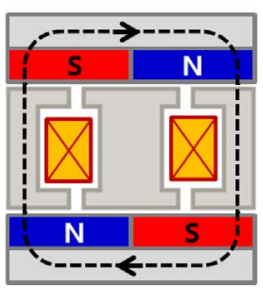

(b) NS type DR-SS

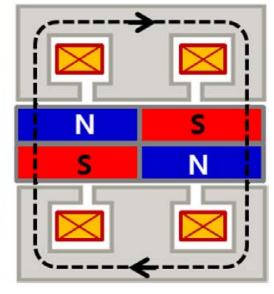

(c) SR-DS
Fig. 1. (Color online) Multistage AFPM generator structures and their main flux flows.

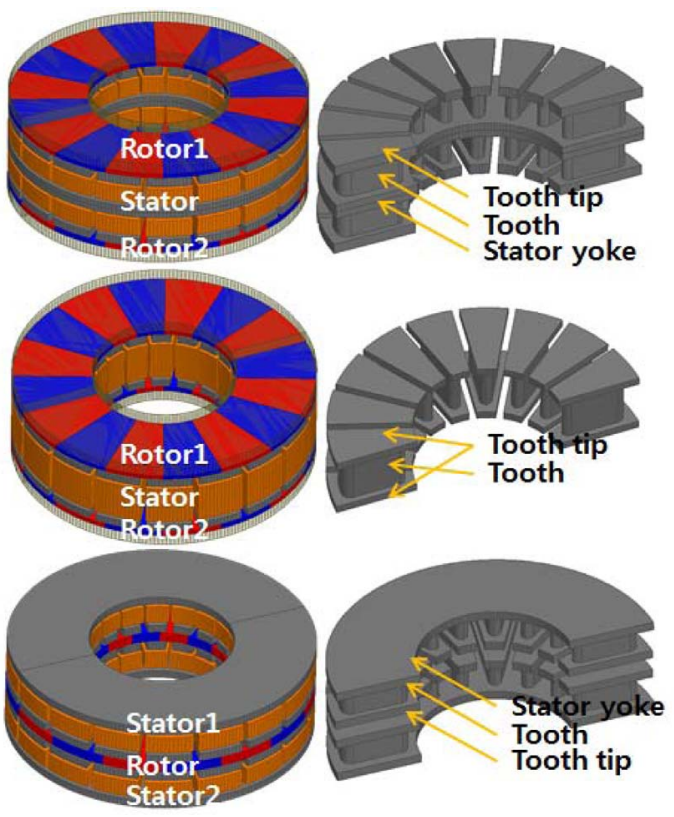

Fig. 2. (Color online) The configurations of the three multistage AFPMs (left) and each cross section of the stator cores (right): (upper) NN type DR-SS, (middle) NS type DR-SS, and (lower) SR-DS.

Fig. 2 shows the three-dimensional (3-D) models and cross-sectional models of the stator cores to provide a better understanding of the differences in the structure of the three topologies.

\section{Optimum Design}

\subsection{Optimum design process and design variables}

Each model was designed with the same optimum design process by the RSM to ensure a fair comparison of the properties for the three multistage structures $[7,8]$. 
This process is roughly classified into a two-step experiment design and response surface analysis, which are further explained in Sections 3.2 and 3.3.

The following assumptions were made to produce the optimum design.

1) The outer diameter, number of turns per phase, and fill factor are the same.

2) The same magnetic materials and same winding conditions are used.

3) The maximum flux density in the middle of the stator yoke and the tooth is under $1.6 \mathrm{~T}$

4) The current density is under $4.5 \mathrm{~A} / \mathrm{mm}^{2}$

The stator yoke thickness, slot width, and PM thickness were selected as the design variables to achieve a high power density and maximum efficiency.

Table 2 shows the three design variables and levels. The values of the design variables in the -1 and +1 levels were determined by selecting possible values for the three design variables as the minimum and maximum, respectively, and the values in the zero level are the middle values for these ranges.

\subsection{Design of experiment}

For the second-order response model, the design of the experiment requires at least three levels for each of the design variables. Therefore, the central composite design (CCD) was adopted as the experimental design method. The sample points were determined by the three basic levels $(-1,0$, and 1$)$, and the additional axis point is $\pm \alpha$. In this study, $\alpha$ is defined as one.

The total number of experiments is the sum of $2^{k}$ and $2 k+1$ where $k$ is the number of design variables. Because the NN-type DR-SS and SR-DS models have three design variables, and the NS-type DR-SS has two design variables, the number of experiments for each of the models is 15 or 9 , as shown in Table 2. A comparison was performed with 27 experiments in full factorial design for the three design variables, and the number of experiments was considerably reduced using CCD.

The results of the CCD and the computer experiment are listed in Tables 3 to 5 for the three models. The computer experiment was performed using 3-D FEA at a load resistance and rotational speed of the generator of 6 ohm per phase and $1800 \mathrm{rpm}$, respectively. To maintain the design assumptions, the maximum flux density in the stator core and the current density were examined during FEA, and the copper loss and core losses were considered to calculate the efficiency. The details of the abbreviations

Table 2. Design variables and levels $(-1,0$, and +1$)$.

\begin{tabular}{lccc}
\hline \hline Design variable and its abbreviation & NN type DR-SS & NS type DR-SS & SR-DS \\
\hline Stator yoke thickness, SyokeT $[\mathrm{mm}]$ & $(2.0,2.5,3.0)$ & - & $(2.5,3.0,3.5)$ \\
Slot width, SlotW [mm] & $(5.0,5.35,5.7)$ & $(5.0,5.35,5.7)$ & $(5.0,5.35,5.7)$ \\
PM thickness, PMT [mm] & $(1.0,1.4,1.8)$ & $(1.0,1.4,1.8)$ & $(2.0,2.8,3.6)$ \\
\hline Number of experiments & 15 & 9 & 15 \\
\hline
\end{tabular}

Table 3. The results of CCD and computer experiments for the NN-type DR-SS.

\begin{tabular}{cccccccc}
\hline \hline Samples & $\begin{array}{c}\text { SyokeT } \\
{[\mathrm{mm}]}\end{array}$ & $\begin{array}{c}\text { SlotW } \\
{[\mathrm{mm}]}\end{array}$ & $\begin{array}{c}\text { PMT } \\
{[\mathrm{mm}]}\end{array}$ & $\begin{array}{c}\text { FDs } \\
{[\mathrm{T}]}\end{array}$ & $\begin{array}{c}\text { CurD } \\
{\left[\mathrm{A} / \mathrm{mm}^{2}\right]}\end{array}$ & $\begin{array}{c}\text { Pout } \\
{[\mathrm{W}]}\end{array}$ & $\begin{array}{c}\text { Efficiency } \\
{[\%]}\end{array}$ \\
\hline 1 & 2 & 5 & 1 & 1.41 & 4.20 & 132.96 & 85.40 \\
2 & 3 & 5 & 1 & 1.50 & 4.37 & 144.24 & 85.86 \\
3 & 2 & 5.7 & 1 & 1.54 & 3.99 & 119.74 & 84.17 \\
4 & 3 & 5.7 & 1 & 1.60 & 4.09 & 126.30 & 84.87 \\
5 & 2 & 5 & 1.8 & 1.51 & 4.68 & 165.42 & 85.82 \\
6 & 3 & 5 & 1.8 & 1.61 & 4.95 & 184.81 & 86.26 \\
7 & 2 & 5.7 & 1.8 & 1.64 & 4.40 & 146.03 & 84.64 \\
8 & 3 & 5.7 & 1.8 & 1.65 & 4.50 & 153.01 & 85.27 \\
9 & 2 & 5.35 & 1.4 & 1.56 & 4.40 & 146.03 & 85.06 \\
10 & 3 & 5.35 & 1.4 & 1.62 & 4.57 & 157.47 & 85.64 \\
11 & 2.5 & 5 & 1.4 & 1.56 & 4.70 & 166.68 & 85.88 \\
12 & 2.5 & 5.7 & 1.4 & 1.64 & 4.36 & 142.66 & 84.83 \\
13 & 2.5 & 5.35 & 1 & 1.55 & 4.23 & 134.48 & 85.13 \\
14 & 2.5 & 5.35 & 1.8 & 1.64 & 4.72 & 167.80 & 85.51 \\
15 & 2.5 & 5.35 & 1.4 & 1.62 & 4.54 & 155.13 & 85.33 \\
\hline
\end{tabular}


Table 4. The results of the CCD and the computer experiments for the NS-type DR-SS.

\begin{tabular}{cccccccc}
\hline \hline Samples & $\begin{array}{c}\text { SyokeT } \\
{[\mathrm{mm}]}\end{array}$ & $\begin{array}{c}\text { SlotW } \\
{[\mathrm{mm}]}\end{array}$ & $\begin{array}{c}\text { PMT } \\
{[\mathrm{mm}]}\end{array}$ & $\begin{array}{c}\text { FDs } \\
{[\mathrm{T}]}\end{array}$ & $\begin{array}{c}\text { CurD } \\
{\left[\mathrm{A} / \mathrm{mm}^{2}\right]}\end{array}$ & $\begin{array}{c}\text { Pout } \\
{[\mathrm{W}]}\end{array}$ & $\begin{array}{c}\text { Efficiency } \\
{[\%]}\end{array}$ \\
\hline 1 & - & 5 & 1 & 1.55 & 4.49 & 152.37 & 88.91 \\
2 & - & 5.7 & 1 & 1.63 & 4.17 & 131.89 & 87.98 \\
3 & - & 5 & 1.8 & 1.64 & 5.04 & 192.13 & 89.20 \\
4 & - & 5.7 & 1.8 & 1.65 & 4.55 & 156.36 & 88.16 \\
5 & - & 5 & 1.4 & 1.62 & 4.84 & 177.52 & 89.08 \\
6 & - & 5.7 & 1.4 & 1.65 & 4.42 & 148.06 & 88.13 \\
7 & - & 5.35 & 1 & 1.59 & 4.34 & 142.72 & 88.46 \\
8 & - & 5.35 & 1.8 & 1.65 & 4.82 & 175.35 & 88.76 \\
9 & - & 5.35 & 1.4 & 1.64 & 4.65 & 163.94 & 88.65 \\
\hline
\end{tabular}

Table 5. The results of the CCD and the computer experiments for the SR-DS.

\begin{tabular}{cccccccc}
\hline \hline Samples & $\begin{array}{c}\text { SyokeT } \\
{[\mathrm{mm}]}\end{array}$ & $\begin{array}{c}\text { SlotW } \\
{[\mathrm{mm}]}\end{array}$ & $\begin{array}{c}\text { PMT } \\
{[\mathrm{mm}]}\end{array}$ & $\begin{array}{c}\text { FDs } \\
{[\mathrm{T}]}\end{array}$ & $\begin{array}{c}\text { CurD } \\
{\left[\mathrm{A} / \mathrm{mm}^{2}\right]}\end{array}$ & $\begin{array}{c}\text { Pout } \\
{[\mathrm{W}]}\end{array}$ & $\begin{array}{c}\text { Efficiency } \\
{[\%]}\end{array}$ \\
\hline 1 & 2.5 & 5 & 2 & 1.49 & 4.37 & 143.98 & 85.85 \\
2 & 3.5 & 5 & 2 & 1.52 & 4.43 & 147.69 & 86.29 \\
3 & 2.5 & 5.6 & 2 & 1.59 & 4.14 & 129.99 & 85.04 \\
4 & 3.5 & 5.6 & 2 & 1.60 & 4.19 & 132.73 & 85.58 \\
5 & 2.5 & 5 & 3.6 & 1.62 & 4.95 & 184.24 & 86.26 \\
6 & 3.5 & 5 & 3.6 & 1.63 & 5.01 & 189.06 & 86.73 \\
7 & 2.5 & 5.6 & 3.6 & 1.65 & 4.59 & 158.59 & 85.40 \\
8 & 3.5 & 5.6 & 3.6 & 1.65 & 4.60 & 159.81 & 85.91 \\
9 & 2.5 & 5.3 & 2.8 & 1.61 & 4.59 & 159.13 & 85.68 \\
10 & 3.5 & 5.3 & 2.8 & 1.63 & 4.64 & 162.40 & 86.19 \\
11 & 3 & 5 & 2.8 & 1.59 & 4.77 & 171.98 & 86.35 \\
12 & 3 & 5.6 & 2.8 & 1.64 & 4.45 & 149.47 & 85.56 \\
13 & 3 & 5.3 & 2 & 1.56 & 4.30 & 139.41 & 85.69 \\
14 & 3 & 5.3 & 3.6 & 1.64 & 4.81 & 174.24 & 86.13 \\
15 & 3 & 5.3 & 2.8 & 1.62 & 4.63 & 161.76 & 85.99 \\
\hline
\end{tabular}

used in Tables 3 to 5 are as following: SyokeT, stator yoke thickness; SlotW, the slot width; PMT, PM thickness; FDs, the maximum flux density in the stator core; CurD, current density; and Pout, output power.

\subsection{Response Surface Analysis}

The response surface analysis was used to find the relationship between the design variables and the results of the experiment by a statistical fitting method. Four objective functions were used to represent the maximum flux density in the stator core, current density, output power, and efficiency to achieve a high power density and high efficiency, while conforming to the design assumptions. The Minitab program was used to generate the objective function and perform the response surface analysis. Various response surfaces were investigated and analyzed depending on conditions in the program, and Figs. 3 to 5 show the response surfaces of efficiency and power according to the design variables for each of the three multistage AFPMs.

The results indicating the optimal point for each model are listed in Table 6; the optimum conditions achieved the highest efficiency and above $150 \mathrm{~W}$ output power, conforming to the design assumptions.

\section{Design Results and Comparisons}

3-D FEA was performed for each model to ensure the reliability of the optimum design results obtained by RSM, and the optimized dimensions are listed in Table 6. The expectations from the RSM and the results of FEA produced an error of below $1 \%$ in the terminal voltage, output power, and efficiency, as shown in the last three lines of Table 7. Therefore, the reliability of the optimum design was confirmed.

Figure 6 shows the external circuit for the 3-D FEA, 

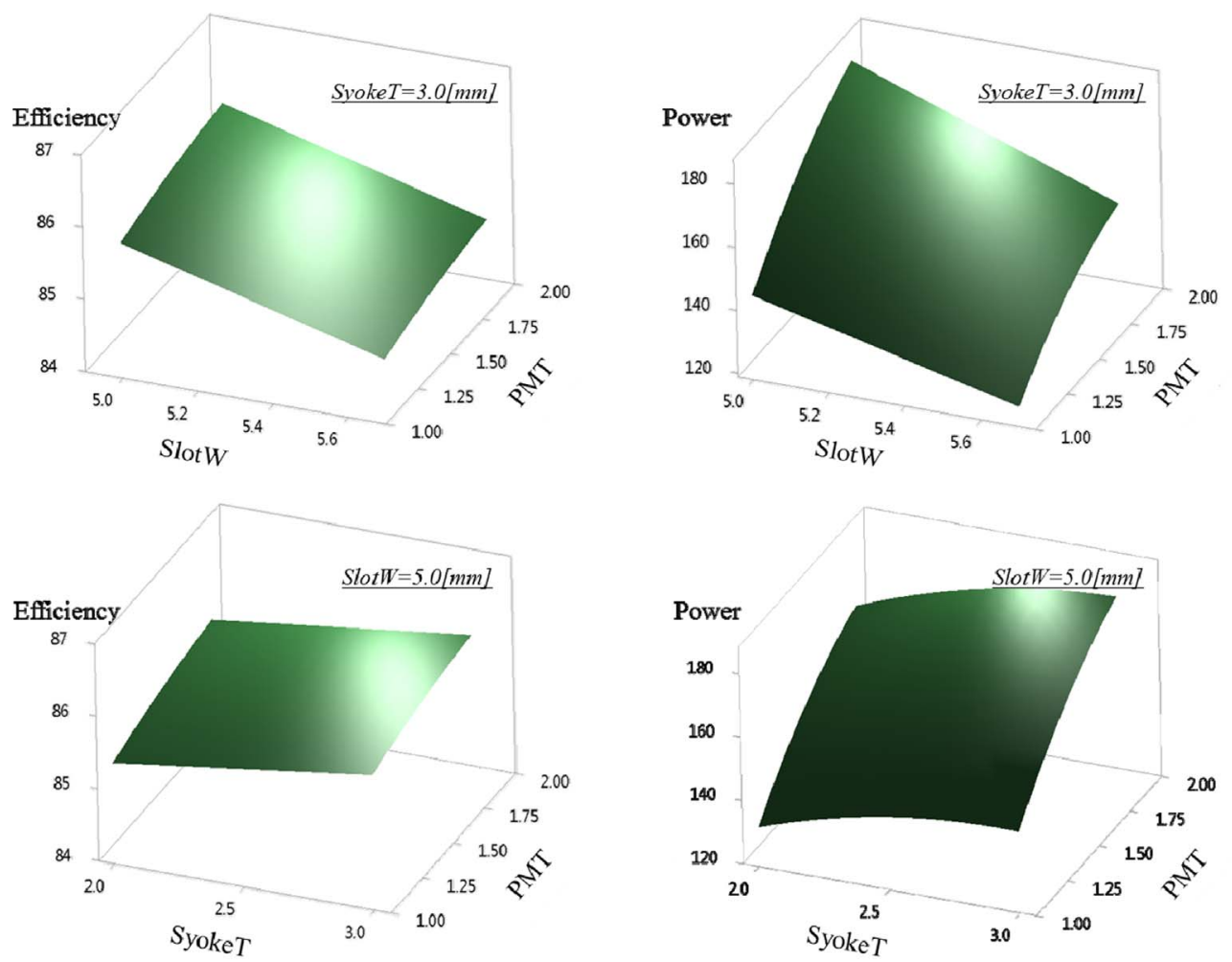

Fig. 3. (Color online) The response surfaces of efficiency and power for NN type DR-SS.
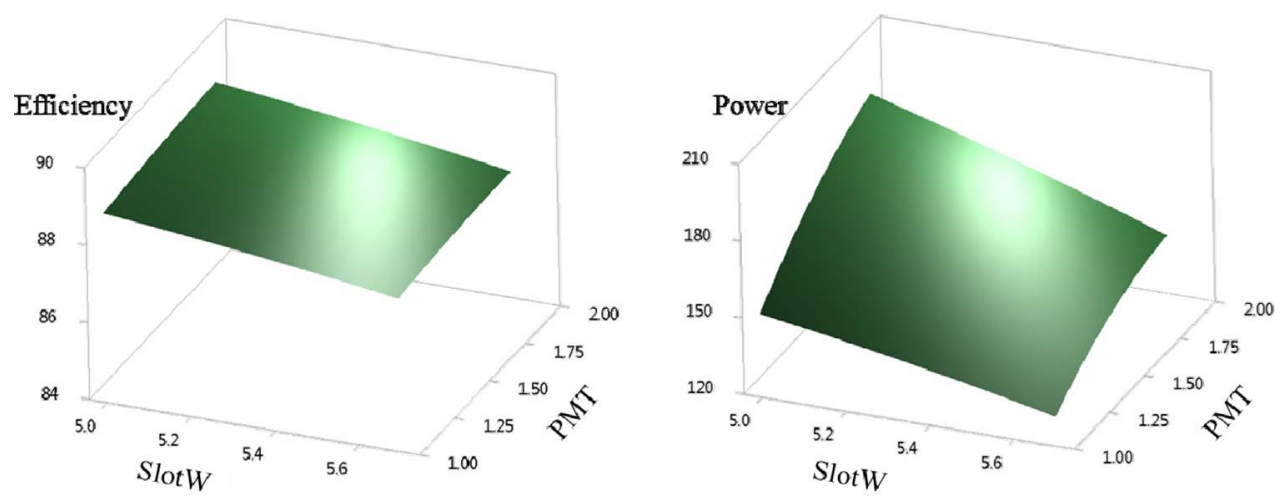

Fig. 4. (Color online) The response surfaces of efficiency and power for NS type DR-SS.

Table 6. Optimum design results obtained with RSM and the output characteristics.

\begin{tabular}{lccc}
\hline \hline Design variables & NN type DR-SS & NS type DR-SS & SR-DS \\
\hline SyokeT [mm] & 3.0 & - & 3.5 \\
SlotW [mm] & 5.0 & 5.0 & 5.0 \\
PMT [mm] & 1.1 & 1.0 & 2.1 \\
Phase voltage [Vrms] & 17.1 & 17.2 & 17.1 \\
Output power [W] & 152.2 & 152.5 & 151.7 \\
Efficiency [\%] & 85.9 & 88.9 & 86.3 \\
\hline
\end{tabular}

and half of each configuration on the left in Fig. 2 was used as the models for magnetic field analysis. At a load resistance $\left(R_{\text {load }}\right)$ of $6 \mathrm{ohm}$ per phase and the speed of the generator of $1,800 \mathrm{rpm}$, the analysis result waveforms such as electro-motive force (EMF), terminal voltage, and current are shown in Fig. 7. Because the analysis result waveforms of the three models are similar, the only waveforms of $\mathrm{NN}$ type DR-SS is presented representatively. A comparison of the root-mean-square ( $\mathrm{rms}$ ) values of the voltage and current of the three models is shown in 

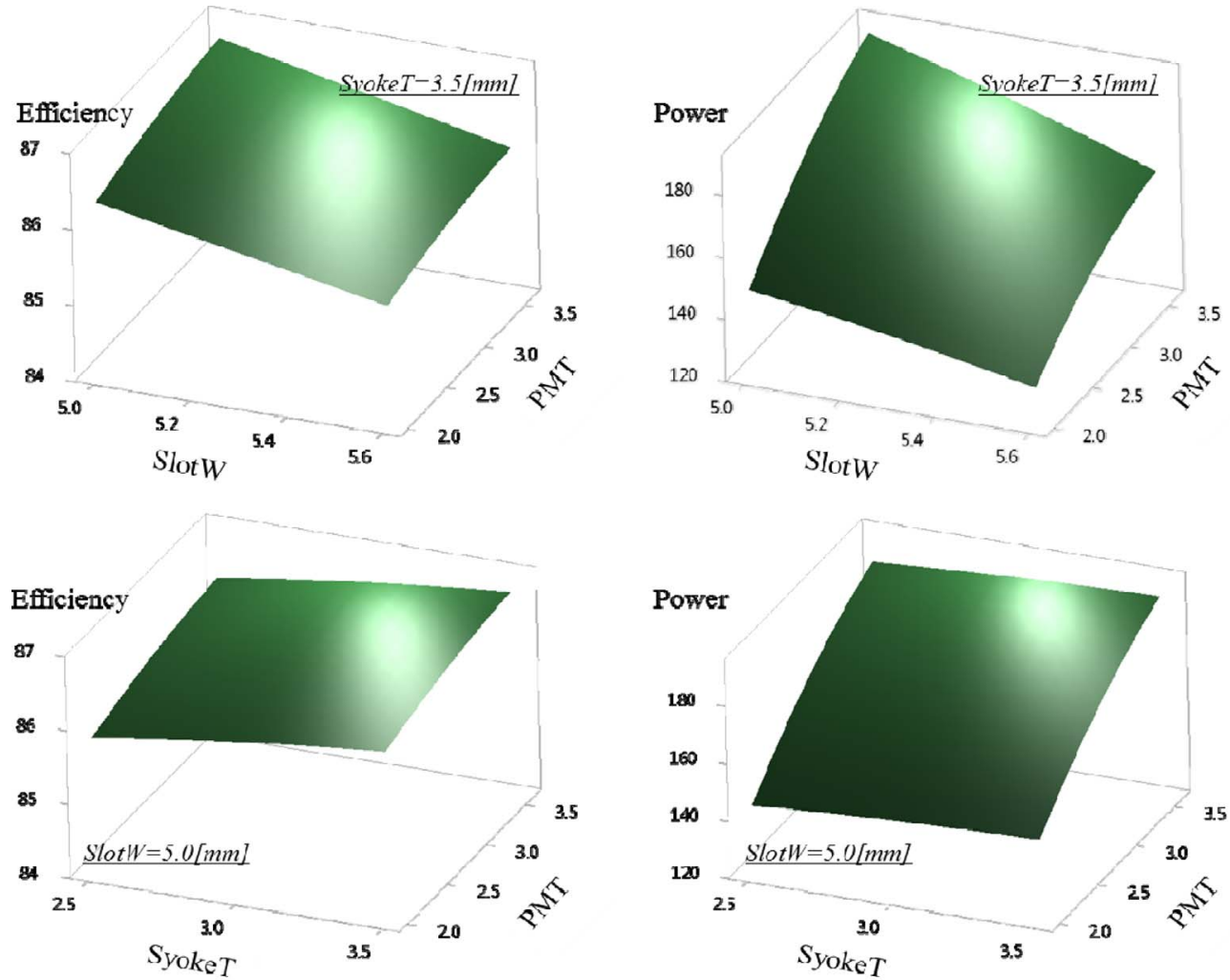

Fig. 5. (Color online) The response surfaces of efficiency and power for SR-DS.

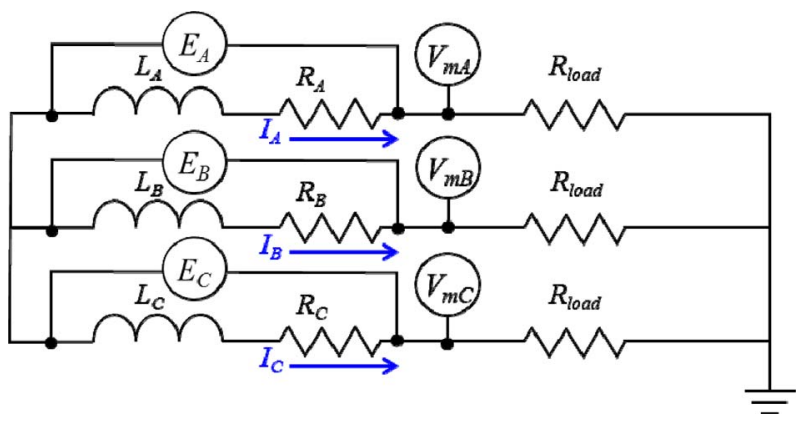

Fig. 6. (Color online) The external circuit for 3-D FEA. $\left(R_{\text {load }}\right.$ $\left.=6 \mathrm{Ohm}, R_{A}=R_{B}=R_{C}=0.22 \mathrm{Ohm}\right)$.

Table 7 .

The EMF waveforms contain lots of harmonics, because of load-current, and the average total harmonic distortion (THD) of EMFs is above 9\%. However, the average THDs of the terminal voltages and currents are below $1 \%$, because of the grounded Y-connection.

A comparison of all of the major dimensions and output characteristics of the three optimized models is shown in Table 7, indicating that the NS-type DR-SS topology is the best in both the criteria. It is possible for efficiency to be higher and the volume to be smaller, because there is

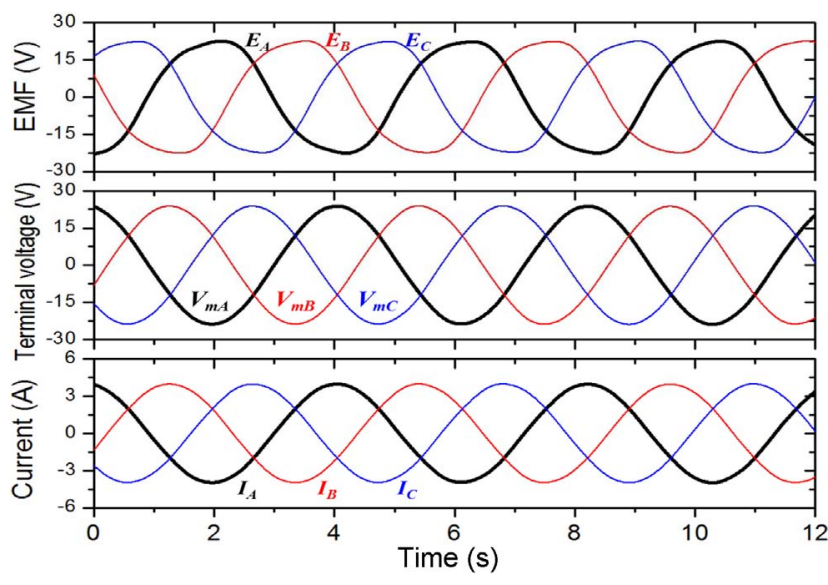

Fig. 7. (Color online) The analysis results waveform of $\mathrm{NN}$ type DR-SS.

no stator yoke, and both the core loss and core volume were reduced by as much as the amount corresponding to the stator yoke.

\section{Results and Discussion}

The NS-type DR-SS system expected to have the best performance was fabricated and experimentally evaluated. 
Table 7. FEA results of the optimal designed models.

\begin{tabular}{|c|c|c|c|c|}
\hline \multicolumn{2}{|l|}{ Contents } & NN type DR-SS & NS type DR-SS & SR-DS \\
\hline \multicolumn{2}{|l|}{ Stator height [mm] } & 24 & 17 & 25 \\
\hline \multicolumn{2}{|l|}{ Rotor height $[\mathrm{mm}]$} & 9.2 & 9 & 2.1 \\
\hline \multicolumn{2}{|l|}{ Overall height [mm] } & 34.2 & 27 & 28.1 \\
\hline \multicolumn{2}{|l|}{ Outer diameter $[\mathrm{mm}]$} & 85.0 & 85.0 & 85.0 \\
\hline \multicolumn{2}{|l|}{ Coil/PM/core volume $\left[\mathrm{cm}^{3}\right]$} & 11.6/9.7/98.6 & $11.6 / 8.8 / 70.3$ & 11.6/9.3/72.1 \\
\hline \multicolumn{2}{|l|}{ Overall volume $\left[\mathrm{cm}^{3}\right]$} & 194.1 & 153.2 & 159.5 \\
\hline \multicolumn{2}{|l|}{ Overall weight [kg] } & 0.92 & 0.70 & 0.71 \\
\hline \multicolumn{2}{|l|}{ Terminal voltage [Vrms] } & 17.1 & 17.1 & 17.1 \\
\hline \multicolumn{2}{|l|}{ Phase current [Arms] } & 2.85 & 2.86 & 2.85 \\
\hline \multicolumn{2}{|l|}{ THD of EMF [\%] } & 9.59 & 9.70 & 8.90 \\
\hline \multicolumn{2}{|c|}{ THD of terminal voltage [\%] } & 1.11 & 0.88 & 0.74 \\
\hline \multicolumn{2}{|l|}{ THD of current [\%] } & 1.11 & 0.88 & 0.74 \\
\hline \multicolumn{2}{|l|}{ Output power [W] } & 151.9 & 152.4 & 151.7 \\
\hline \multicolumn{2}{|l|}{ Core losses [W] } & 19.5 & 13.6 & 18.6 \\
\hline \multicolumn{2}{|l|}{ Copper losses [W] } & 5.38 & 5.38 & 5.37 \\
\hline \multicolumn{2}{|l|}{ Efficiency [\%] } & 85.9 & 88.9 & 86.3 \\
\hline \multicolumn{2}{|c|}{ Output power density $\left[\mathrm{W} / \mathrm{cm}^{3}\right]$} & 0.78 & 0.99 & 0.95 \\
\hline \multirow{3}{*}{$\begin{array}{l}\text { Error between RSM and } \\
\text { FEA [\%] }\end{array}$} & Terminal voltage & 0.4 & 0.1 & 0.1 \\
\hline & Output power & 0.2 & 0.1 & 0.0 \\
\hline & Efficiency & 0.0 & 0.0 & 0.0 \\
\hline
\end{tabular}

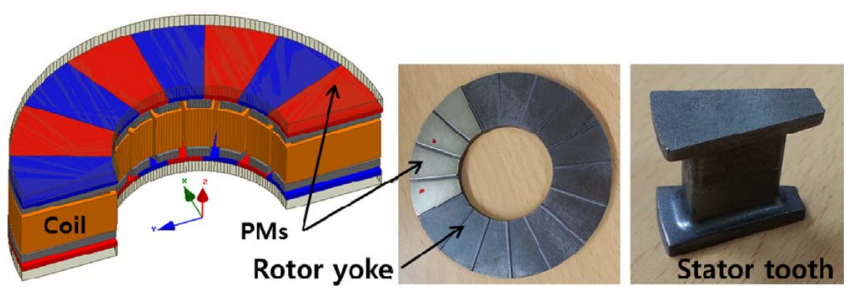

Fig. 8. (Color online) 3-D FEA model and fabricated cores of the NS-type DR-SS.

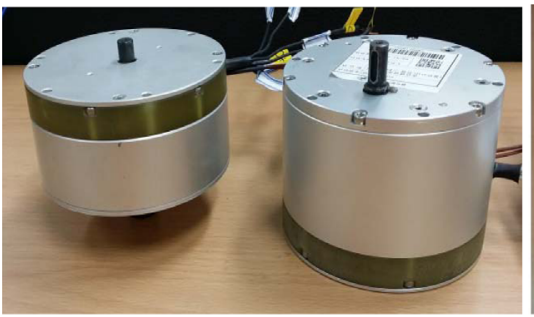

(a) Gearless generator (b) Geared generator

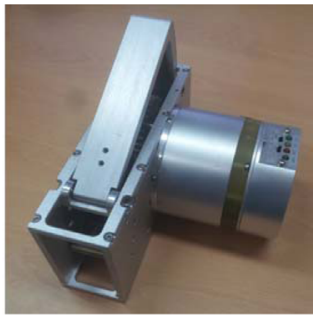

(c) Generating system
Fig. 9. (Color online) Gearless generator and Geared generator made of the NS type DR-SS AFM, and the generating system.

Figure 8 shows the 3-D FEA model and the main fabricated components. The components were assembled, and the fabricated prototypes are shown in Fig. 9 with the gearless generator, geared generator, and a $100 \mathrm{~W}$ portable generating system. The gearless generator is made up of

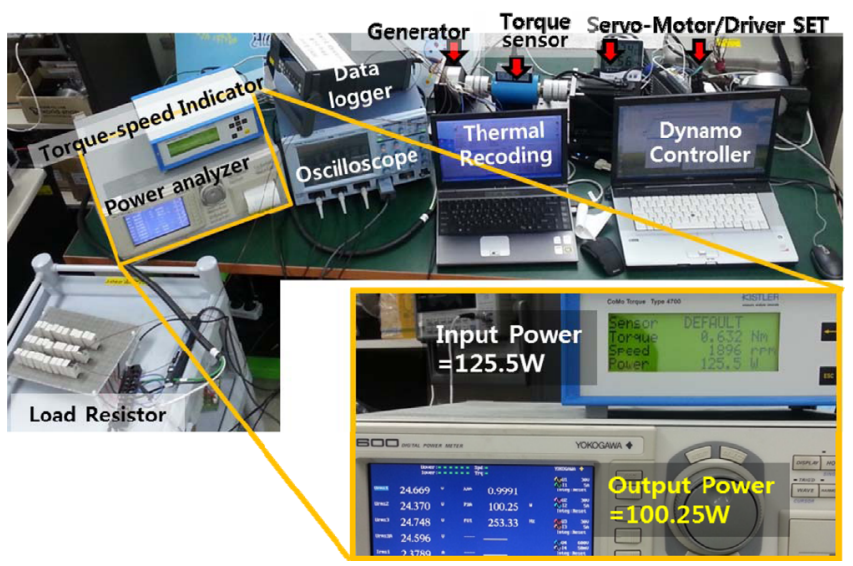

Fig. 10. (Color online) Configuration of the experimental system and the test results for the rated power.

only NS-type DR-SS AFM, and the geared generator is built by attaching the gear to the gearless generator. The generating system consists of a crank, power converter, and the geared generator.

Figure 10 shows the experimental setup configured to examine the characteristics of the manufactured generator. The performance of the NS-type DR-SS AFM was evaluated by conducting a test with the gearless generator. Figure 11 shows the measured terminal voltage and current waveforms, and the THDs of these waveforms 


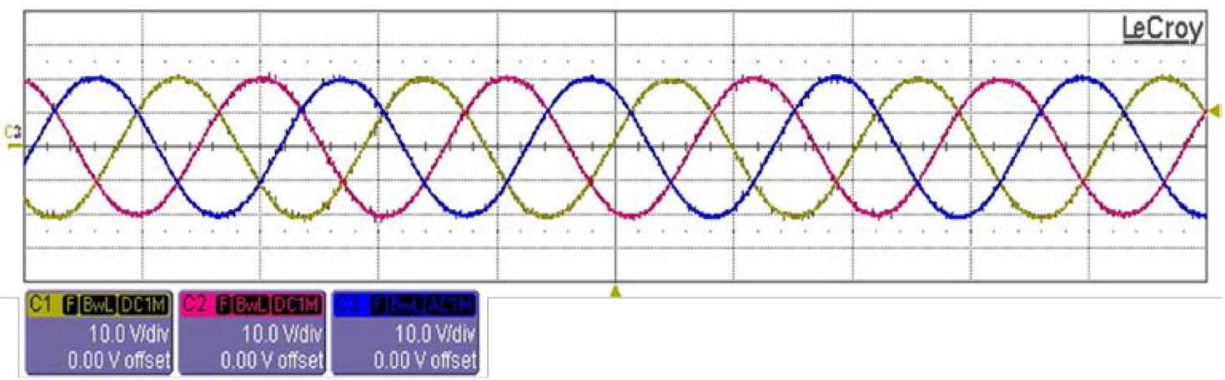

(a) terminal voltage waveforms

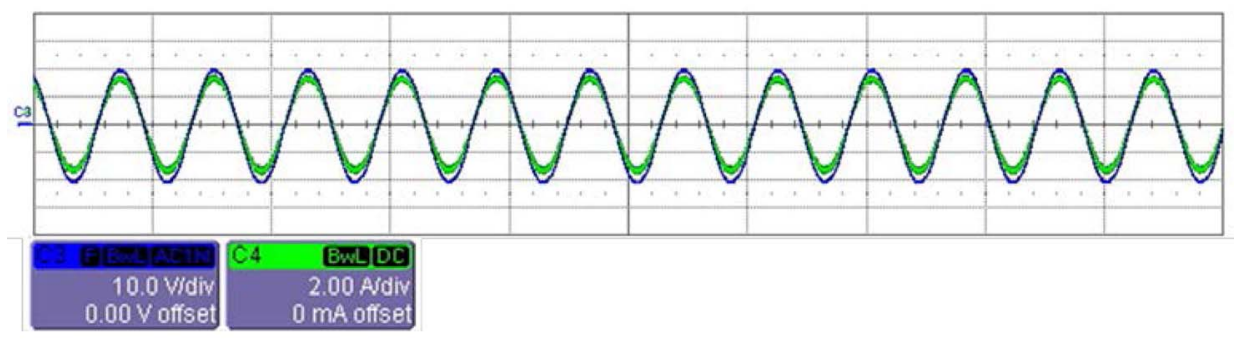

(b) Terminal voltage and current waveforms

Fig. 11. (Color online) Measured terminal voltage and current waveforms.

were below 1\%, as expected (Fig. 7 and Table 7). However, the measured rms value of the terminal voltage was $15 \mathrm{~V}$, whereas the calculated one was $17.1 \mathrm{~V}$ as listed in Table 7. On this account, the characteristics including the output power and efficiency also have difference between the calculated and measured values. The input and output powers were 125.5 and $100.25 \mathrm{~W}$, respectively, with a load resistance and speed of the generator of $6 \mathrm{ohm}$ per phase and $1900 \mathrm{rpm}$ (a crank speed of $63 \mathrm{rpm}$ ), respectively. A difference was observed between the measured efficiency $(80.0 \%)$ and the calculated efficiency $(88.9 \%)$, probably because of the fact that the efficiency was calculated by only considering the copper loss and core losses, but the measured efficiency is more complicated and various forms of loss such as mechanical and thermal losses can also occur. Moreover, the manufacturing tolerance and the measurement errors could also contribute to the gap in these values.

Therefore, the process to select a proper generator for a $100 \mathrm{~W}$ generating system is described, and this study can offer guidance to examine an AFM for small-seized, high power system applications.

\section{Acknowledgements}

This work was supported by the Primary of the Korea Electrotechnology Research Institute (KERI) and the Next Generation Military Battery Research Center program of Defense Acquisition Program Administration and Agency for Defense Development (ADD).

\section{References}

[1] T. F. Chan, W. Wang, and L. L. Lai, IEEE Trans. Energy Convers 25, 669 (2010).

[2] F. Marignetti, V. D. Colli, and S. Carbone, IEEE Trans. Magn. 46, 598 (2010).

[3] J. Lee, D. Koo, S. Moon, and C. Han, IEEE Trans. Magn. 48, 2977 (2012).

[4] T. J. Woolmer and M. D. McCulloch, Hybrid Vehicle Conference, IET, 27 (2006).

[5] T. J. Woolmer and M. D. McCulloch, Electric Machines \& Drives Conference, IEMDC'07, 1 (2007).

[6] J. Lee, B. Park, and D. Koo, J. Magn. 19, 309 (2014).

[7] J. Park, S. Kim, J. Hong, and J. Lee, IEEE Trans. Magn. 42, 3479 (2006).

[8] J. Xie, D. Kang, B. Woo, J. Lee, Z. Sha, and S. Zhao, J. Electrical Engineering \& Technology 7, 745 (2012). 